\title{
Comparison of the effect of GC tooth mousse and fluoride varnish on dentin hypersensitivity reduction.
}

1. BDS, FCPS

Assistant Professor Operative Dentistry

Watim Dental College, Rawalpindi.

2. BDS

Post-graduate Resident Operative Dentistry

Lahore Medical and dental College Lahore.

3. BDS, FCPS

Assistant Professor Prosthodontics Watim Dental College, Rawalpindi.

4. BDS, MCPS

Senior Registrar Prosthodontics

Watim Dental College, Rawalpindi.

5. BDS, FCPS

Assistant Professor Oral and

Maxillofacial Surgery

Watim Dental College,

Rawalpindi.

6. BDS, M.Phil

Assistant Professor Oral Pathology

Watim Dental College, Rawalpindi.

Correspondence Address:

Dr. Ammarah Afreen

Department of Operative Dentistry

Watim Dental College, Rawalpindi.

ammarahafreen@gmail.com

Article received on:

27/10/2020

Accepted for publication:

01/02/2021
Ammarah Afreen ${ }^{1}$, Sabah Shahzad Kiani ${ }^{2}$, Zarah Afreen ${ }^{3}$, Sadia Daaniyal ${ }^{4}$, Eruj Shuja ${ }^{5}$, Gulmina Saeed Orakzai ${ }^{6}$

ABSTRACT... Objective: To compare the mean dentin hypersensitivity after using GC tooth mousse versus fluoride varnish in patients with dentinal hypersensitivity due to non-carious cervical lesions. Study Design: Randomized Control Trial. Setting: Watim Dental College, Rawalpindi. Period: February to August 2019. Material \& Methods: A total number of 166 patients were enrolled in the study. Informed consent and demographic information were taken. The subjects were randomized by using random number table to minimize bias. Patients were divided into 2 groups. Fluoride varnish (group 1) which is the control group and GC Tooth Mousse which is group 2, both were used 3 times in the first day during the first week. On follow up the tooth sensitivity was noted. The follow up appointment to measure the level of dentinal hypersensitivity was done after the given treatment on the $7^{\text {th }}$ day of the first week. For measuring the dentin hypersensitivity, the Visual Analogue Scale was used. The data that was collected was entered and 1 then it was analyzed on SPSS version 21. Results: In this study mean age of the fluoride varnish group patients was $44.14 \pm 8.95$ years, in GC tooth mousse group patients was $44.24 \pm 9.04$ years. The mean pain score of fluoride varnish group patients was $1.98 \pm 1.43$ while in GC Tooth Mousse paste group patients was $2.39 \pm 1.21$ ( $p$-value $=0.048$ ). Conclusion: Fluoride varnish group showed significantly lower mean dentin hypersensitivity than to GC tooth mousse group in patients with dentinal hypersensitivity with caries free cervical lesions.

Key words: $\quad$ Cervical Lesions, Caries, Dentin Hypersensitivity, Fluoride Varnish, GC Tooth Mousse.

Article Citation: Afreen A, Kiani SS, Afreen Z, Sadia. Comparison of the effect of GC tooth mousse and fluoride varnish on dentin hypersensitivity reduction. Professional Med J 2021; 28(4):598-604.

https://doi.org/10.29309/TPMJ/2021.28.04.6183

\section{INTRODUCTION}

Dentinal hypersensitivity occurs as a result of exposed dentin. It is generally characterized by pain that is sharp in character and short in duration. This typically occurs in response to external stimuli and no dental defect or pathology can explain the above mentioned symptoms. The external stimuli that can elicit dentin hypersensitivity include evaporative, thermal, tactile, osmotic or chemical forces. An individual's everyday activities, such as drinking, brushing, eating, and sometimes even breathing is hindered by the pain that occurs as a result of dentin hypersensitivity. Patients usually prefer over the counter products and do not seek any treatment for dentin hypersensitivity. ${ }^{2}$ Estimates of the prevalence of dentin hypersensitivity vary. $9-30 \%$ of the adult population suffers from dentin hypersensitivity according to Kielbassa, whereas $50 \%$ of the general population and $100 \%$ of the patients who have some periodontal conditions have experienced Dentin hypersensitivity at some time in their lives according to Dowell, et al. ${ }^{3}$

Dentin hypersensitivity is more prevalent in females and is frequently observed between the age group of 20 and 50 years. The teeth most commonly affected by this condition are the canines, premolars, and molars. It mostly involves the facial surfaces of teeth near the cervical border. Dentin hypersensitivity has a multifactorial etiology. Most common clinical cause is gingival recession. ${ }^{1}$ Less common causes of Dentin Hypersensitivity include erosion, attrition, bleaching, cracked teeth and smoking. 
Several theories exist to explain Dentin Hypersensitivity. The most accepted theory is the hydrodynamic theory which is presented by Astron and Brannstorm. ${ }^{1}$ The stimuli (thermal, evaporative, tactile) stimulates the fluid flow within dental tubules. This fluid flow triggers the baroreceptors near the pulp, leading to sensation of pain. According to the hydrodynamic theory of pain there must be exposed dentin surface as well as patent tubules that will allow fluid flow to reach the dental pulp where the baroreceptors are present. ${ }^{3}$ The treatment of dentin hypersensitivity should focus on closing the dentinal tubules either by precipitation of crystals in tubule lumen or by hydroxyapatite melting. ${ }^{2}$ The most widespread treatments of dentin hypersensitivity involve application of desensitizing agents and materials such as high-concentration fluoride varnishes. A large number of studies have been published for the treatment of Dentin Hypersensitivity. However, still no consensus has been reached on which product constitutes the "gold standard" for treatment of Dentin Hypersensitivity. ${ }^{4}$

Lukomsky recommended the use of fluoride as a topical desensitizing agent. It has been in use since 1941. The application of fluoride mechanically blocks the transmission of stimulus to the pulp. It does so by the formation of calcium fluoride globules and to some extent fluorapatite. ${ }^{5}$ The use of varnishes with sodium fluoride (in high concentrations) as the active ingredient has been advocated. The use of sodium fluoride increases the time of action of fluoride in contact with exposed dentin. It also enhances its effectiveness in decreasing sensitivity of dentin. ${ }^{6}$ GC Tooth Mousse is a recently used material for the management of dentinal hypersensitivity. It contains amorphous calcium phosphate (ACP) and casein phosphopeptide (CPP). CPP binds to tooth's biofilm and also stabilize amorphous calcium phosphate. It is a milk derived protein. CPP not only results in hard tissue re-mineralization but also has the ability to block the opened and patent dentinal tubules thereby reducing dentin hypersensitivity. ${ }^{7}$

An article shows the comparison of effectiveness of fluoride varnish to GC tooth mousse.
Comparison was done between baseline scores and post treatment scores at $7^{\text {th }}$ day. It was found that there was significant reduction in dentin hypersensitivity in both fluoride varnish group and CPP-ACP paste group. Mean hypersensitivity to ice was $4.66+1.63$ and $4.40+0.96$ at day 7 post treatment in fluoride varnish versus CPPACP paste group respectively. ${ }^{7}$ In another study the mean dentin hypersensitivity was found to be $3.23+0.6$ with fluoride varnish and $3.68+1.33$ with CPP-ACP paste. $^{8}$

There is continuous debate between the dentists that which method is best for relieving the patient from pain. There are two studies conducted so far and both have variable results. Hence, this study is planned to observe the same medication effect in local population. It will lead the dentist to select a method that is more effective in controlling pain.

\section{MATERIAL \& METHODS}

Approval from the hospital ethical committee was obtained for this study (WDC/2019/1098). The study design was Randomized Control Trial. The sampling technique used was non-probability consecutive sampling. Inclusion criteria consisted of both male and female patients with age ranging from 30-60 years, consisting of vital teeth with chief complaint of dentinal hypersensitivity, who at the time of presentation had at least 3 caries free cervical lesions, Tooth Wear Index (TWI) code ' 2 ' and ' 3 ' that is loss of dentin had been less than $2 \mathrm{~mm}$ deep (there is loss of enamel and loss of dentin, but not to the point of exposing secondary dentin or pulp) and patients who were willing to participate in the study and having good oral hygiene. Exclusion criteria consisted of patients with a history of any systemic illnesses like Diabetes(BSF $>200 \mathrm{mg} / \mathrm{dl}$ ), High blood pressure (BP 140/90mmHg), Psychological diseases like Anxiety disorders assessed by clinical examination, Adult Attention Deficit, Bipolar Disorder and previous hospitalization assessed from history of the patients, teeth with dental caries, fractures or cracks in the cervical areas, any restorations that is either unsatisfactory or extensive, multiple restorations, and orthodontic appliance or removable prostheses which involved the cervical areas and patients with a 
history of drug use and those who were either using analgesic and/or anti-inflammatory drugs. As a protocol followed in the hospital, all patients were examined in OPD and those patients who fulfilled the inclusion criteria were referred to Operative dentistry department.

A total of 166 students were enrolled in the current study. Using a WHO sample size calculator (7.4a), level of significance $5 \%$, power of the test $90 \%$, population SD 0.965 , test value of population mean 3.23, anticipated population mean 3.68. Sample size was 79 . Total of 83 patients was taken in each group.

Patientsfulfillingthe inclusion criteriawereselected from the outpatient department of Operative, Watim Medical and Dental College. A written informed consent was taken after explaining the purpose of the study to the patients. The subjects were randomized by using random number table to minimize bias. Patients were divided in 2 groups. The group 1 received the treatment that was based on the fluoride varnish company's instruction (control group) whereas Group 2 patients were under the treatment regimens based on GC Tooth Mousse Paste Company's instruction. Both fluoride varnish and GC Tooth Mousse were used 3 times in the first day during the first week. The follow up appointment to measure the level of dentinal hypersensitivity was done after the given treatment on the $7^{\text {th }}$ day of the first week.

Visual Analog Scale was used for measuring the dentin sensitivity. The patients were asked to put a vertical line on a line of $10 \mathrm{~cm}$ length to describe their tooth sensitivity. On this line, 0 indicates that there is no sensitivity whereas 10 indicate very severe pain. Sensitivity to air was measured in a sensitive tooth for 5 seconds. The follow-up was done after 7 days from the time of application of the agents. Follow up was ensured by keeping contact number and address. A structured preform had specifically designed to record findings of the study.

Data was entered and analyzed using SPSS 21.0. For both qualitative and quantitative variables, descriptive statistics were used. For age, sensitivity scores (quantitative variables), Mean and standard deviation was calculated. For qualitative variables like gender, frequency and percentage was calculated. T-test was used to compare mean hypersensitivity in two educational status groups. P-values $<0.05$ was considered significant. For age, gender and duration of the disease, the data was stratified. Post stratification T test was applied. P-value < 0.05 was considered significant.

\section{RESULTS}

In this study total 166 patients were enrolled out of which 116 (69.88\%) were female and 50 $(30.12 \%)$ were male as shown in pie chart. Male to female ratio of the patients was $0.4: 1$. Both groups, that is, Group A (Fluoride varnish) and Group B (GC tooth mousse paste) consisted of 83 patients each. The mean age of the group $A$ patients was $44.14 \pm 8.95$ years while the mean age of the group B patients was $44.24 \pm 9.04$ years. In group A $25(30 \%)$ patients were male while $58(70 \%)$ patients were females. In group B, 25(30\%) patients were male while $58(70 \%)$ patients were females. The mean duration of hypersensitivity for patients in both Group A and Group $B$ are given in Table-l. The mean pain score of group A patients was $1.98 \pm 1.43$ while in group $B$ patients was $2.39 \pm 1.21$. This difference was statistically significant i.e. $p$-value $=0.048$ as shown in Table-Il.

Data was stratified for age of patients. Among patients with age $\leq 45$ years, the mean pain score was 2.10 \pm 1.37 in group $A$ and $2.19 \pm 1.22$ in group $B \quad(p-v a l u e=0.765)$. Similarly, among patients with age >45years, the mean pain score was $1.80 \pm 1.51$ in group $A$ and $2.60 \pm 1.17$ in group $B$ ( $p$-value $=0.012)$ shown in Table-III. Data was stratified for gender of patients. In male patients, the mean pain score was $2.20 \pm 1.53$ in group $A$ and $2.28 \pm 1.24$ in group $B(p-v a l u e=0.84)$. Similarly, in females, the mean pain score was $1.88 \pm 1.39$ in group $A$ and $2.43 \pm 1.20$ in group $B$ $(p-$ value $=0.024)$.

Data was stratified for duration of hypersensitivity. In patients with duration of hypersensitivity $\leq 6$ 
months, the mean pain score was $2.13 \pm 1.39$ in group $A$ and $2.36 \pm 1.21$ in group $B(p$-value $=0.426)$ as shown in Table-IV. Similarly, in patients with duration of hypersensitivity $>6$ months, the mean pain score was $1.79 \pm 1.47$ in group $A$ and $2.41 \pm 1.22$ in group $B(p-v a l u e=0.043)$.

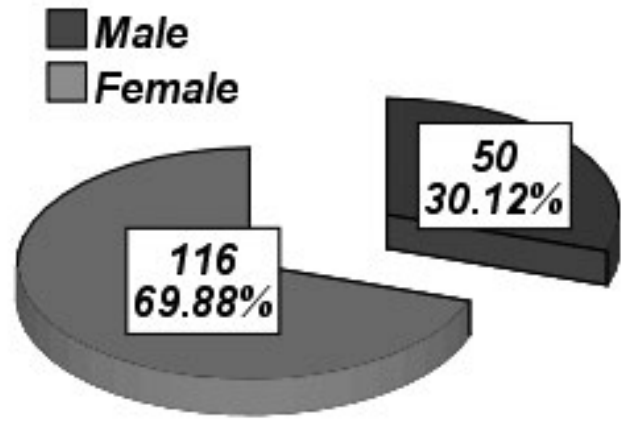

Figer-1. Frequency distribution of gender.

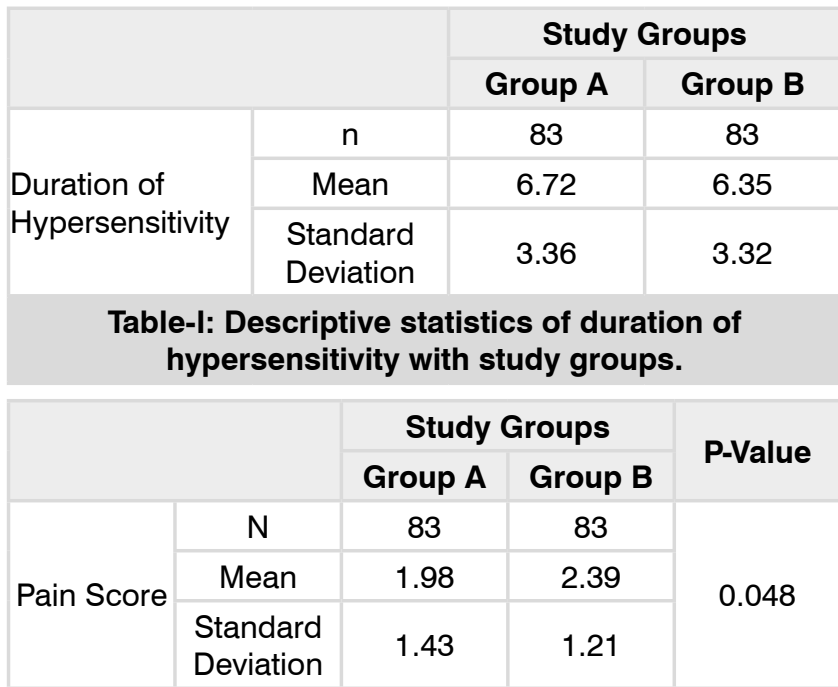

Table-II. Comparison of pain score with study groups.

Group $A=$ Fluoride varnish

Group B=GC Tooth Mousse paste

\begin{tabular}{|c|c|c|c|c|}
\hline \multirow{4}{*}{$\begin{array}{l}\text { Pain } \\
\text { Score }\end{array}$} & \multirow{2}{*}{$\begin{array}{c}\text { Age } \\
\text { (years) }\end{array}$} & \multicolumn{2}{|c|}{ Study Groups } & \multirow{2}{*}{ P-Value } \\
\hline & & Group A & Group B & \\
\hline & $\leq 45$ & $2.10 \pm 1.37$ & $2.19 \pm 1.22$ & 0.765 \\
\hline & $>45$ & $1.80 \pm 1.51$ & $2.60 \pm 1.17$ & $0.012^{*}$ \\
\hline
\end{tabular}

Table-III. Comparison of pain score with study groups stratified by age (years).

Group $A=$ Fluoride varnish

Group $B=G C$ Tooth Mousse paste

\begin{tabular}{|c|c|c|c|c|}
\multirow{4}{*}{$\begin{array}{c}\text { Pain } \\
\text { score }\end{array}$} & $\begin{array}{c}\text { Duration } \\
\text { of } \\
\text { Hyper- } \\
\text { sensitivity }\end{array}$ & \multicolumn{2}{|c|}{ Study Groups } & $\begin{array}{c}\text { P- } \\
\text { Galue }\end{array}$ \\
\cline { 2 - 5 } & $\leq 6$ & $2.13 \pm 1.39$ & $2.36 \pm 1.21$ & 0.426 \\
\hline & $>6$ & $1.79 \pm 1.47$ & $2.41 \pm 1.22$ & 0.043 \\
\hline
\end{tabular}

Table-IV. Comparison of pain score with study groups stratified by duration of hypersensitivity.

Group $A=$ Fluoride varnish

Group B=GC Tooth Mousse paste

\section{DISCUSSION}

In daily clinical practice, one of the most common complaint is of "Dentinal hypersensitivity". Sharp pain of hypersensitivity occurs because of exposed dentine. It occurs in response to various stimuli that include thermal, chemical, tactile or osmotic. Branstrom and coworkers proposed "Hydrodynamic Theory of Dentin Hypersensitivity" which is the most accepted theory for mechanism of dentin hypersensitivity. It postulates that sensitivity of dentin occurs due to displacement of dentinal fluid in the tubules in response to various stimuli.9,10 Our hypothesis was that there is a difference in mean dentin hypersensitivity when after using GC tooth mouse versus fluoride varnish in patients with dentinal hypersensitivity with caries free cervical lesions. In our trial, the mean pain score of group $A$ patients was $1.98 \pm 1.43$ while in group $B$ patients was $2.39 \pm 1.21$. P-value $=0.048$ is found to be significant.

Dentin hypersensitivity can be managed by various agents who include both physical and chemical agents. Examples of such agents include fluoride compounds, varnishes, calcium compounds, oxalates, strontium chloride, and lasers. These agents have been found to be effective in management of dentin hypersensitivity. ${ }^{11,12}$ Different data studies show different results when effectiveness of these different agents in decreasing dentine hypersensitivity is measured. An article shows the comparison of effectiveness of fluoride varnish to GC tooth mousse. Comparison was done between baseline scores and post treatment scores at $7^{\text {th }}$ day. It was found that there was significant reduction in dentin 
hypersensitivity in both fluoride varnish group and CPP-ACP paste group. Mean hypersensitivity to ice was $4.66+1.63$ and $4.40+0.96$ at day 7 post treatment in fluoride varnish versus CPPACP paste group respectively. ${ }^{7}$ In another study the mean dentin hypersensitivity was found to be $3.23+0.6$ with fluoride varnish and $3.68+1.33$ with CPP-ACP paste. $^{8}$

Navya Puvvula et al conducted a study to compare the effect of fluoride Varnish, Fluoride releasing composite, and CPP-ACP fluoride on demineralization around bracket. The author demonstrated that in GC tooth mousse group, the lesion depth was reduced by $67.4 \%$. However in the bifluoride lesion group, the lesion depth was reduced by $70 \% .{ }^{13} \mathrm{~A}$ study by DeyuHu et al presented that the Arginine Mouthwash that uses Pro-Argin Mouthwash Technology provides a significant reduction in dentin hypersensitivity as compared to Negative Control mouthwash (in an alcohol free base) after eight week of use. The Pro-Argin contains alcohol-free base. The other ingredients include $0.8 \%$ arginine, PVM/MA copolymer, pyrophosphates, and $0.05 \%$ sodium fluoride. ${ }^{14}$

Hansen et al. showed that $50 \%$ of teeth with dentin hypersensitivity were relieved when sodium fluoride varnish was applied on them. ${ }^{15}$ Erosion is not reduced by application of fluoride However, acidified fluoride gel has shown to protect the eroded enamel. ${ }^{16,17}$ One study by Mahtab Memarpour et al concluded that WSL size and dmft index values in primary teeth was significantly reduced by the application of fluoride in conjunction with oral hygiene instructions. ${ }^{18}$

Stannous fluoride is available in variety of formulations. It is available as $0.4 \% \mathrm{gel}, 1.1 \% \mathrm{gel}$ or sodium fluoride in a $0.5 \%$ mouth rinse. Fluoride reduces the permeability of dentin by causing precipitation of insoluble calcium fluoride in the dentinal tubules. This results in blockage of open dentinal tubules and dentin hypersensitivity is reduced. ${ }^{19}$ Recently, GC Tooth Mousse Plus has been introduced. It contains 990 ppm fluoride. The addition of fluoride not only causes occlusion of tubule but also results in remineralization. ${ }^{20}$
Hence both fluoride varnish and Tooth mousse help in decreasing dentine hypersensitivity as showed by different data researches. Our research also helps in proving the efficacy of fluoride varnish and GC tooth mousse in decreasing dentine hypersensitivity. It also showed that fluoride varnish group showed significantly lower the mean dentin hypersensitivity than to GC tooth mousse group.

The limitations of this study were short-term follow up (01 week), study was not placebo controlled or double-blinded, pain is a subjective experience and depends on different factors, for example the psychological profile, previous pain experience and anxiety level of the patient. Therefore, great inter and intra-individual variations are common in pain studies and hence were found in this study too. The most common stimuli (blast of air) used, apparently simple and reliable is not that effective. According to the external temperature, the temperature of air varies. This results in different responses as individual thresholds may or may not be exceeded. The distance from the source of application, air pressure and stimulation time may vary. This gives different intensities of the stimulus, thus leading to change in results.

Long-term follow-up studies are required to overcome the limitations mentioned above. Studies should be double-blinded, randomized and placebo-controlled. It is conceivable that more effective therapies can be developed by further exploring the mechanism underlying dentin hypersensitivity.

\section{CONCLUSION}

Within the limitations of this study, it is concluded that fluoride varnish group showed significantly lower the mean dentin hypersensitivity than to $\mathrm{GC}$ tooth mousse group in patients with dentinal hypersensitivity with caries free cervical lesions.

Copyright $($ )

\section{REFERENCES}

1. Torwane NA, Hongal S, Goel P, BR C, Jain M, Saxena E, et al. Effect of two desensitizing agents in reducing dentin hypersensitivity: An in-vivo comparative clinical trial. J. Clin Diagn Res. 2013; 7(9):2042-46 
2. KVV Prasad, R Sohoni, STikare, M Yalamalli, G Rajesh, SB Javali. Efficacy of two commercially available dentifrices in reducing dentinal hypersensitivity. Indian J Dent Res. 2010; 21(2):224-30.

3. Torwane NA, Hongal S, Goel P, Chandrashekar B, Jain M, Saxena E. A clinical efficacy of $30 \%$ ethenolic extract of Indian propolis and Recaldent ${ }^{\mathrm{TM}}$ in management of dentinal hypersensitivity: A comparative randomized clinical trial. Eur J of Dent. 2013; 7(4):461-8.

4. Porto IC, Andrade AK, Montes MA. Diagnosis and treatment of dentinal hypersensitivity. J Oral Sci 2009; $51(3): 323-32$.

5. Pandit N, Gupta R, Bansal A. Comparative evaluation of two commercially available desensitizing agents for the treatment of dentinal hypersensitivity. Indian J Dent Res 2012; 23(6):778-83.

6. Jain PR, Naik GD, Uppor SA, Kamath DG. Diode laser and fluoride varnish in the management of dentin hypersensitivity. J Interdiscip Dentistry 2015; 5(2):71.

7. Pishevar L, Farhad SZ, Mirzakhani M, Haghayegh $\mathrm{N}$, Ansarinejad M. Comparison the effect of casein phosphopeptide amorphous calcium phosphate and fluoride varnish on dentin hypersensitivity reduction. Caspian J Dent Res 2015; 4(2):20-6.

8. Maghaireh G, Alzraikat H, Guidoum A. Assessment of the effect of casein phosphopeptide-amorphous calcium phosphate on postoperative sensitivity associated with in-office vital tooth whitening. Operative dentistry 2014; 39(3):239-47.

9. Bocci V. How ozone acts and how it exerts therapeutic effects. Ozone: The revolution in Dentistry London: Quintessence Publishing Co 2004:15-22.

10. Holmes J. Clinical reversal of root caries using ozone, double $\square$ blind, randomized, controlled 18-month trial. Gerodontology 2003; 20(2):106-14.

11. Zhong Y, Liu J, Li X, Yin W, He T, Hu D, et al. Effect of a novel bioactive glass $\square$ ceramic on dentinal tubule occlusion: An in vitro study. Aust Dent J. 2015; 60(1):96-103.
12. Anastasiou A, Strafford S, Posada-Estefan O, Thomson C, Hussain S, Edwards $T$, et al. $\beta$-pyrophosphate: A potential biomaterial for dental applications. Materials Science and Engineering: C 2017; 75:885-94.

13. Puvvula N, Pathuri S, Priya CP, Prakash AS. Comparison of effect of fluoride varnish, fluoride releasing composite, and casein phosphopeptide amorphous calcium phosphate fluoride on demineralization around brackets: An in vivo study. J Indian Orthod Soc 2014; 48(2):105.

14. Hu D, Stewart B, Mello S, Arvanitidou L, Panagakos F, De Vizio W, et al. Efficacy of a mouthwash containing $0.8 \%$ arginine, PVM/MA copolymer, pyrophosphates, and $0.05 \%$ sodium fluoride compared to a negative control mouthwash on dentin hypersensitivity reduction. A randomized clinical trial. J Dent 2013; 41:S26-S33.

15. Hansen EK. Dentin hypersensitivity treated with a fluoride $\square$ containing varnish or a light $\square$ cured glass $\square$ ionomer liner. Eur J Oral Sci. 1992; 100(6):305-9.

16. Cooper JS, Bokmeyer TJ, Bowles WH. Penetration of the pulp chamber by carbamide peroxide bleaching agents. JOE 1992; 18(7):315-7.

17. Haywood VB. Treating sensitivity during tooth whitening. Compendium of continuing education in dentistry (Jamesburg, NJ: 1995) 2005; 26(9 Suppl 3):11-20.

18. Memarpour M, Fakhraei E, Dadaein S, Vossoughi $M$. Efficacy of fluoride varnish and casein phosphopeptide-amorphous calcium phosphate for demineralization of primary teeth: A randomized clinical trial. Med PrincPract 2015; 24(3):231-7.

19. Morris M, Davis R, Richardson B. Clinical efficacy of two dentin desensitizing agents. Am J of Dent. 1999; 12(2):72-6.

20. Walsh LJ. The effects of GC Tooth Mousse on cervical dentinal sensitivity: A controlled clinical trial. International Dentistry South Africa 2010; 12(1):412. 


\begin{tabular}{|c|c|c|c|}
\hline \multicolumn{4}{|c|}{ AUTHORSHIP AND CONTRIBUTION DECLARATION } \\
\hline Sr. \# & Author(s) Full Name & Contribution to the paper & Author(s) Signature \\
\hline 1 & Ammarah Afreen & $\begin{array}{l}\text { Data collection, Statistics, } \\
\text { Literature review. }\end{array}$ & Ach \\
\hline 2 & Sabah Shahzad Kiani & $\begin{array}{l}\text { Original idea of research, } \\
\text { Literature review. }\end{array}$ & Se些 \\
\hline 3 & Zarah Afreen & $\begin{array}{l}\text { Data collection, Statistics, } \\
\text { Literature review. }\end{array}$ & $2 a \cdot 2$ \\
\hline 4 & Sadia Daaniyal & $\begin{array}{l}\text { Data collection, Literature } \\
\text { reveiw. }\end{array}$ & \\
\hline 5 & Eruj Shuja & Literature reveiw. & \\
\hline 6 & Gulmina Saeed Orakzai & Literature reveiw. & butuexe \\
\hline
\end{tabular}

